\title{
Implikasi Brand Image dan Kualitas Layanan Hotel terhadap Kepuasan Pelanggan
}

\author{
Fanny Oryzativa ${ }^{1}$ dan Niken Febrina Ernungtyas ${ }^{2 *}$ \\ ${ }_{1,2}^{2}$ Sekolah Tinggi Ilmu Komunikasi Inter Studi \\ Email: fannyorztv@gmail.com ; niken@stikom.interstudi.edu²* \\ *corresponding author
}

\section{Keywords:}

Brand Image, Service Quality, Customer Satisfaction, Behavioral Intentions.
Kata Kunci:

Citra Merek, Kualitas Layanan, Kepuasan pelanggan, Niat Perilaku.

\begin{abstract}
The purpose of the study is to describe the influence of brand image and hotel service quality on customer satisfaction and intention. There are four dimensions of service quality that increase the potential to influence customer satisfaction; employee behavior, room facilities, protection, and food quality. This study used a quantitative approach and the data were collected by a questionnaire that was adopted and adapted from previous studies. The survey was conducted by issuing questionnaires to 30 Swiss-bell hotel customers provided in Sector 2 of Blok SA, Jl. Metro Pondok Indah, South Jakarta, which was then analyzed using simple linear regression analysis to analyze the influence brand image and service quality on customer satisfaction. The results showed that customer satisfaction and brand image produced the greatest influence at 0.920. Get the lowest results from physical evidence and customer satisfaction that only get results of 0.282. This study shows that service quality is important in the hospitality industry. It increased customer satisfaction and stimulate positive behavioral intentions to be realized, such as customer loyalty and behavior for the intention to recommend to families and others and that can also increase positive motivation for others which can be realized. The findings suggest professional in the hotel sector must get to improve the quality because it is a potential to gain customer satisfaction.
\end{abstract}

\begin{abstract}
ABSTRAK
Tujuan dari penelitian ini adalah untuk menggambarkan pengaruh citra merek dan kualitas pelayanan hotel terhadap kepuasan dan niat pelanggan. Ada empat dimensi kualitas layanan yang meningkatkan potensi untuk mempengaruhi kepuasan pelanggan; perilaku karyawan, fasilitas kamar, perlindungan, dan kualitas makanan. Penelitian ini menggunakan pendekatan kuantitatif dan data dikumpulkan dengan kuesioner yang diadopsi dan diadaptasi dari penelitian sebelumnya. Survei dilakukan dengan mengeluarkan kuesioner kepada 30 pelanggan hotel Swiss-bell yang disediakan di Sektor 2 Blok SA, Jl. Metro Pondok Indah, Jakarta Selatan, yang kemudian dianalisis menggunakan analisis regresi linier sederhana untuk menganalisis pengaruh merek dan kualitas layanan terhadap kepuasan pelanggan. Hasil penelitian menunjukkan bahwa kepuasan pelanggan dan citra merek menghasilkan pengaruh terbesar di 0,920. Dapatkan hasil terendah dari bukti fisik dan kepuasan pelanggan yang hanya mendapatkan hasil 0,282. Studi ini menunjukkan bahwa kualitas layanan penting dalam industri perhotelan. Ini meningkatkan kepuasan pelanggan dan merangsang niat perilaku positif untuk direalisasikan, seperti loyalitas pelanggan dan perilaku untuk niat untuk merekomendasikan kepada keluarga dan orang lain dan itu juga dapat meningkatkan motivasi positif bagi orang lain yang dapat direalisasikan. Temuan menyarankan profesional di sektor perhotelan harus meningkatkan kualitas karena berpotensi untuk mendapatkan kepuasan pelanggan.
\end{abstract}

Copyright (C) 2020 Channel Jurnal Komunikasi. All right reserved. 


\section{PENDAHULUAN}

Di Indonesia bisnis pariwisata ini cukup memiliki kekuatan atau kemampuan mengingat bahwa Indonesia secara alami banyak memiliki keunikan budaya, keindahan alam, dan lain sebagainya. Semua kekuatan atau kemampuan itu, akan menjadi modal utama di dalam industri pariwisata. Kelemahan dari industri pariwisata itu sendiri yang harus diakui adalah karena industri ini bersifat masif dan massal yang pastinya akan melibatkan banyak orang diluar sana jadi harus ada sebuah proses atau interaksi yang menghasilkan suatu keseimbangan yang harmonis sehingga akan menghasilkan hasil yang positif. Dari sisi lain, industri pariwisata juga sangat sensitif terhadap isu keamanan, semua isu keamanan itu langsung berdampak pada industri pariwisata seluruhnya termasuk bagian perhotelan. Menurut Pramadivara \& Seminari (2014), hotel merupakan suatu hal yang terkait dengan pembelian dan penjualan produk atau jasa yang produknya menyediakan tempat menginap, makanan dan lainnya. Saat ini, pada proses yang cukup panjang, yang akhirnya telah berkembang di bisnis perhotelan dan pariwisata di Indonesia mengalami peningkatan yang cukup tinggi dan besar. Pada sisi lain bisa kita lihat peningkatan jumlah wisatawan dan berkembang nya atau bertambahnya hotel yang ada di Indonesia ini.

Setelah diketahui secara umum, ternyata sekitar $60 \%$ pengunjung adalah wisatawan mancanegara. Angka tersebut juga karena dukungan pemerintah setempat yang mengadakan acara-acara untuk mempromosikan wisata asli Indonesia serta meningkatnya pengunjung hotel. Menurut Ardahaey (2011), peningkatan jumlah pengunjung dapat menyebabkan peningkatan pendapatan bisnis. Ini karena semakin tinggi jumlah pengunjung, maka akan lebih tinggi pengeluaran mereka. Sedangkan wisatawan yang datang untuk menginap di hotel mungkin berkontribusi pada pendapatan hotel, kehadiran mereka juga memberikan dampak positif pada pendapatan penduduk lokal. Bukti-bukti diberikan oleh masa lalu studi menunjukkan bahwa kualitas layanan terkait dengan kepuasan pelanggan (Parasuraman et al., 1994) dan loyalitas pelanggan (Caruana, 2002; Kandampully et al., 2011). Pelanggan yang puas memiliki efek positif pada organisasi dalam hal profitabilitas, pembelian berulang, loyalitas merek, dan dari mulut ke mulut yang positif (Angelova \& Zekiri, 2011). Pemasaran hotel adalah sebuah aktivitas yang menggunakan beberapa strategi atau cara yang telah direncanakan dengan baik guna untuk menyampaikan informasi terkait pelayanan produk dan jasa yang dapat diberikan oleh sebuah hotel, dengan memberikan sesuatu pesan unik atau informasi yang membuat seluruh tamu hotel akan mendapatkan keuntungan dengan pelayanan dan kinerjanya sebuah hotel tersebut. (Atmaja \& Ruliana, 2017). Dengan demikian, operator hotel harus lebih fokus pada penyediaan yang lebih baik guna meningkatkan kualitas layanan untuk memenuhi kebutuhan pelanggan, yang bertujuan untuk menghindari hal-hal yang tidak diinginkan atau yang berdampak negatif dari kualitas layanan yang lebih rendah. Misalnya, bisnis hotel yang tidak memiliki layanan kualitas mungkin menghadapi masalah seperti kepuasan pelanggan negatif, kurangnya loyalitas pelanggan dan keunggulan kompetitif yang lebih rendah (Dedeoğlu \& Demirer, 2015).

Kualitas layanan dianggap sebagai salah satu kunci keberhasilan organisasi. Ini berarti memberikan kualitas layanan terbaik kepada pelanggan adalah suatu kemenangan strategi dan akan meningkatkan laba perusahaan. Tingkat layanan yang sangat baik tidak hanya akan menghasilkan peningkatan laba, tetapi juga memberi energi karyawan untuk melakukan potensi penuh mereka untuk memenuhi tantangan yang dihadapi oleh bisnis atau pekerjaannya di bidang masing-masing karyawan. Dengan memberikan layanan berkualitas, hotel dapat mencapai kepercayaan pelanggan dan dengan demikian mendapatkan keunggulan kompetitif (Gunarathne, 2014). Menurut Rao (2013), operator hotel kini fokus pada pemeliharaan kualitas yang lebih baik standar seperti ini memiliki keuntungan yang jelas untuk memenuhi kebutuhan dan harapan dasar pelanggan.

Di industri perhotelan, membangun merek komitmen seumur hidup yang bisa mendatangkan rujukan dan persentase pengulangan bisnis yang tinggi. Citra merek juga mempengaruhi keputusan pembelian pelanggan. Pembelian pelanggan tertuju karena adanya ketertarikan kepada pelayanan serta fasilitas hotel yang diberikan kepada pelanggan. Keputusan pembelian biasanya dikarenakan pelanggan tersebut telah mengetahui isi atau identitas hotel tersebut dan juga melengkapi kebutuhan customer itu sendiri. Maka dari itu, keputusan pembelian sangat mempengaruhi citra merek dan pada akhir keputusan konsumen akan beranggapan positif tentang merek tersebut. (Ikhsana et al., 2019). Merek atau brand yang sudah terkenal akan mempengaruhi pelanggan untuk memiliki rasa nyaman dari hati pelanggan itu sendiri. Misalnya, pelanggan tidak mempunyai pengalaman dengan suatu produk atau belum pernah membeli suatu produk atau jasa, pelanggan akan lebih memiliki rasa percaya terhadap merek yang lebih terkenal dibandingkan produk yang belum pernah dibeli. Semua para konsumen pasti banyak yang beranggapan bahwa merek yang terkenal akan jauh lebih terpercaya. Maka dari itu dibutuhkannya tenaga marketing atau promosi untuk mempertahankan serta meningkatkan merek atau brand tersebut. Nilai merek mengacu pada seluruh aset yang dimiliki oleh suatu merek, nilai komponen suatu merek terdiri dari kesadaran pada merek, dipengaruhi oleh merek, kepercayaan pada merek, asosiasi tentang merek, citra merek, dan pengabdian kepada elemen merek. Alasan menguji efek dari semua komponen nilai merek pada pengabdian kepada merek adalah bahwa pengabdian ini sudah dianggap sebagai salah satu dari komponen yang sangat penting untuk mempertahankan dan membangun hubungan jangka panjang dengan pelanggan. Meskipun citra merek diakui sebagai kekuatan pendorong aset merek dan kinerja merek, beberapa penelitian telah menguraikan hubungan antara merek citra dan ekuitas merek (Zhang et al., 2011). Berdasarkan definisi ini, dimungkinkan untuk mengklaim bahwa Merek Gambar dibuat di benak sebagai hasil dari persepsi konsumen tentang produk atau layanan dan sebagai hasil dari upaya pemasaran merek. Dengan kata lain, konsumen mungkin memiliki citra di benak mereka dengan bantuan asosiasi tentang merek. 
Oleh karena itu, kepuasan pelanggan sebagai hasil dari layanan berkualitas yang disediakan sangat penting bagi operator hotel karena secara langsung dapat mempengaruhi loyalitas pelanggan, niat perilaku dan mempertahankan citra merek (brand image). Pemilihan Hotel Swiss-Bel yang berlokasi di Sektor 2 Blok SA, Jl. Metro Pondok Indah yang merupakan hotel ke-57 yang berada di bawah jaringan Swiss-Bel Hotel International. Sebagaimana hotel bintang 4, Hotel Swiss-Bel memiliki 159 kamar, menyediakan fasilitas internet gratis, menyediakan kolam renang termasuk spa, pijat dan lain sebagainya. Peneliti sangat tertarik untuk meneliti lebih lanjut terkait dengan layanan kualitas, citra merek, kepuasan pelanggan dan niat perilaku pada konsumen Hotel Swiss-Bel. Kuesioner diterapkan untuk para pengunjung yang mengunjungi hotel Swiss Bell Pondok Indah. Salah satu tujuan dari penelitian ini adalah untuk menggambarkan pengaruh Brand Image dan kualitas pelayanan hotel pada kepuasan pelanggan perilaku.

\section{A. Kualitas Layanan}

Kualitas layanan telah muncul sebagai elemen penting dalam industri perhotelan selama beberapa dekade. Dalam hubungan ini, penyedia layanan harus memahami harapan pelanggan dan persepsi serta faktor-faktor yang mempengaruhi evaluasi dan kepuasan mereka layanan yang diberikan kepada mereka. Sementara itu, kualitas layanan berkonsentrasi pada bagaimana memenuhi harapan pelanggan seperti yang disebutkan sebelumnya. Pelanggan harapan terdiri dari berbagai atribut layanan. Atribut inilah yang berkontribusi terhadap niat beli dan persepsi mereka terhadap kualitas layanan (Mamilla et al., 2013; Marković \& Janković, 2013)

Sub-bagian berikut membahas tentang elemen yang dipelajari dalam kualitas layanan:

\section{Perilaku karyawan}

Hotel telah menjadi lebih kompetitif dalam beberapa tahun terakhir hingga sekarang, mereka tidak hanya memiliki kamar yang menarik untuk memikat pelanggan. Mereka juga menyediakan 'staf berkualitas tinggi', dianggap sebagai salah satu fasilitas hotel (Rao, 2013). Selain itu, Caber \& Albayrak (2014) menyoroti atribut staf tersebut seperti kesopanan dan keramahan penting untuk meningkatkan kepuasan pelanggan karena memenuhi permintaan pelanggan untuk layanan yang ramah dan sopan. Berdasarkan alasan diatas, hipotesis berikut ini dirumuskan:

H1: Ada hubungan positif antara perilaku karyawan dan pelanggan kepuasan.

\section{Fasilitas Kamar}

Wisatawan menganggap kualitas kamar sebagai faktor yang paling mempengaruhi kemauan mereka membayar untuk hotel ekonomis. Dortyol et al. (2014) menggambarkan daya tarik dan dekorasi kamar sebagai yang utama dimensi yang berdampak positif pada kepuasan tamu dan keputusan mereka untuk merekomendasikan hotel kepada orang lain. Selanjutnya, Karunaratne \& Jayawardena (2011) memeriksa jurusan faktor yang berkontribusi terhadap kepuasan pelanggan. Mereka menemukan bahwa ukuran ruangan dan kualitas furniture diberi skor tertinggi karena mereka mempengaruhi pelanggan harapan dan persepsi. Ini menyiratkan bahwa atribut seperti itu memainkan peran penting dalam hal keputusan pelanggan untuk mengulangi tinggal di hotel, rekomendasikan hotel untuk orang lain dan ini juga menunjukkan kesetiaan terhadap hotel. Berdasarkan pemikiran diatas, maka hipotesis berikut dikembangkan:

H2: Ada hubungan positif antara fasilitas kamar dan kepuasan pelanggan.

\section{Bukti fisik}

Variabel lain yang memainkan peran penting dalam mempengaruhi kepuasan pelanggan adalah bukti fisik. Ini mengacu pada fisik penampilan dan fasilitas yang disediakan oleh hotel. Secara khusus, (Marković \& Janković, 2013) menemukan bahwa secara fisik, penampilan fasilitas hotel, dan peralatan dan materi komunikasi telah menghasilkan efek yang signifikan dan positif pada keseluruhan kepuasan pelanggan untuk industri hotel. Setelah itu, hipotesis berikut dikembangkan:

H3: Ada hubungan positif antara bukti fisik dan kepuasan pelanggan.

\section{Kualitas makanan}

Pelanggan hotel sering mempertimbangkan layanan restoran ketika memilih hotel. Ini mengacu pada kualitas makanan, dan layanan yang ramah dan profesional. Naseem et al. (2011) menemukan bahwa rasa dan variasi makanan memiliki berdampak pada kebahagiaan dan kepuasan pelanggan. Yang penting, kebersihan makanan persiapan merupakan faktor penting dalam penyediaan layanan berkualitas dalam makanan dan departemen minuman. Dalam keterangan di atas, hipotesis berikut adalah dirumuskan:

H4: Ada hubungan positif antara kualitas makanan dan kepuasan pelanggan.

\section{B. Kepuasan pelanggan}

Untuk mencapai kepuasan pelanggan, suatu organisasi perlu menyediakan barang dan layanan yang mengakomodasi tingkat tertentu dari nilai yang dirasakan pelanggan. Dalam urutan untuk mengoperasikan hotel dengan sukses sehingga memberikan pelanggan pengalaman yang memuaskan, hotel manajer perlu mengetahui apa yang diinginkan atau disukai oleh pelanggan dan bagaimana pelanggan itu menilai layanan hotel tersebut. (Olorunniwo et al., 2006). Secara khusus, 
pelanggan kepuasan dapat dinilai dari segi minat; kenikmatan; mengherankan; marah; pilihan yang bijak; dan melakukan hal yang benar.

\section{Niat perilaku}

Haruskah ada hubungan positif antara kepuasan pelanggan dan perilaku niat di sektor hotel dan perhotelan penting karena dampak positifnya bahwa hubungan seperti itu membawa keuntungan (Han \& Back, 2008). Pemahaman tentang sikap pelanggan dapat dilihat melalui pengukuran tingkat kepuasan mereka memberi penyedia layanan kesempatan yang lebih baik untuk mempengaruhi perilaku konsumen. Satu referensi untuk kutipan oleh Siddiqi (2011) yang menunjukkan bahwa atribut kualitas layanan positif terkait dengan kepuasan pelanggan dan pada akhirnya pun kepuasan pelanggan ini berhubungan sangat baik untuk mendapatkan suatu loyalitas pelanggan. Biasanya, pelanggan hotel yang puas dengan pelayanannya, mereka akan merekomendasikan hotel dengan cara obrolan dari mulut ke mulut kepada keluarga atau orang lain. Dalam keterangan di atas, hipotesis berikut adalah dirumuskan:

H5: Ada hubungan positif antara kepuasan pelanggan dan niat perilaku.

\section{Citra Merek}

Citra Merek merupakan bagian dari proses dimana sebuah objek ditangkap oleh indra seseorang, kemudian muncul sebuah konsep yang akan diungkapkan kembali. Mempunyai citra merek yang baik dan bagus tentu akan membuat konsumen dalam melakukan pembelian. (Trilia Sovani et al., 2016). Semua konsumen yang mempunyai pandangan yang baik terhadap suatu merek atau brand, akan lebih memiliki niat untuk melakukan pembelian. Citra dari sebuah merek akan menjadi sebuah jaminan terhadap kualitas dari produk atau jasa yang telah dijual. Sebuah perusahaan yang memiliki citra yang baik akan lebih mudah untuk memasarkan dan mengembangkan produknya kepada konsumen. Kepuasan pelanggan memiliki arti penting bagi perusahaan kecil maupun perusahaan besar. Kepuasan pelanggan membuat sebuah perusahaan mempunyai Brand Image yang positif. Jika pelanggan puas pada sebuah perusahaan termasuk didalam penelitian ini (Hotel Swiss Bell Pondok Indah), pasti akan meningkatkan citra perusahaan itu sendiri. Dalam terang di atas, hipotesis berikut adalah dirumuskan:

H6: Ada hubungan positif antara kepuasan pelanggan dan citra merek.

Citra merek telah menjadi salah satu yang paling tujuan penting untuk setiap pemasaran aktivitas. Pelanggan menyimpulkan kualitas dari sebuah produk dengan citra mereknya, yang selanjutnya mempengaruhi perilaku pembelian. Citra merek akan membuat sebuah nama baik citra perusahaan jika konsumen yang datang pada Hotel Swiss Bell Pondok indah merasa puas pada semua kualitas layanan di hotel itu, lalu muncullah sebuah kepuasan pelanggan. Marković \& Janković (2013) menemukan bahwa secara fisik, penampilan fasilitas hotel, dan peralatan dan materi komunikasi telah menghasilkan efek yang signifikan dan positif pada keseluruhan kepuasan pelanggan untuk industri hotel. Biasanya, konsumen yang puas pada kualitas layanan di hotel itu akan mempromosikan kepada keluarga, teman, bahkan dari mulut ke mulut. Citra merek pun akan mempengaruhi pelanggan baru memiliki keinginan untuk membeli produk atau mencoba produk yang belum pernah dan mempengaruhi pelanggan lama untuk menggunakan kembali jasa hotel tersebut. Berdasarkan pemikiran diatas, hipotesis berikut dirumuskan:

H7: Ada hubungan positif antara citra merek dan niat perilaku.

Gambar 1 di bawah ini menggambarkan kerangka teori yang menggambarkan hubungan antara variabel. Kisah hubungan didasarkan pada ulasan yang relevan literatur.

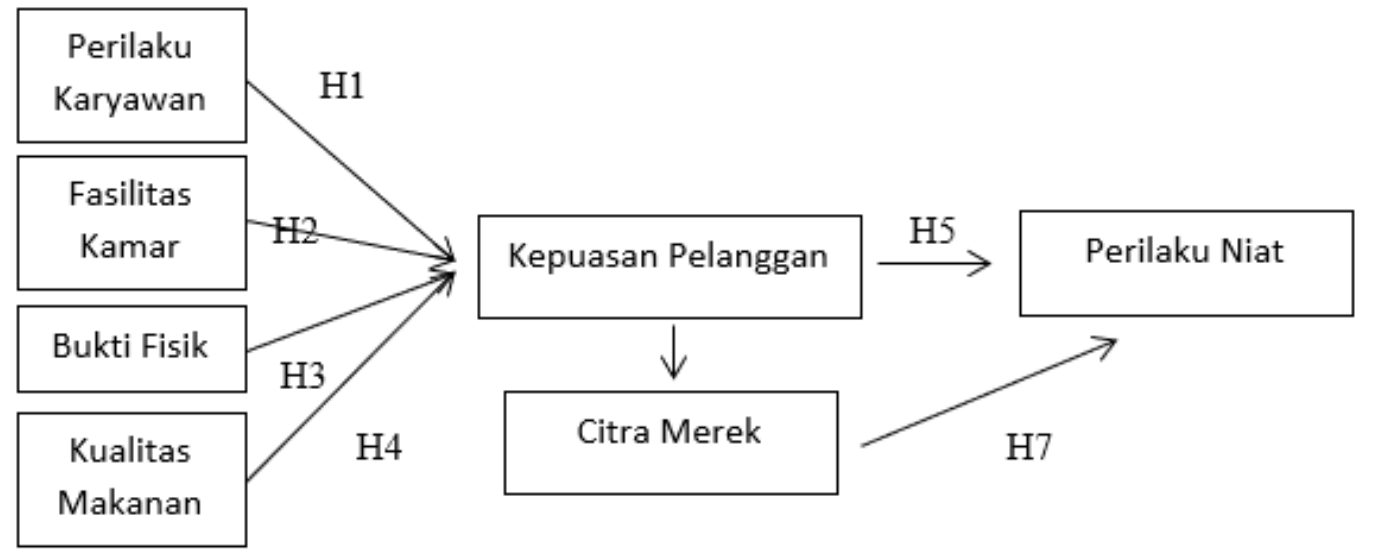

Gambar 1: Kerangka teori penelitian Sumber: Diadopsi dari Padlee, S.F., Thaw, C.Y., Zulkifli, S.N.A., 2019. 


\section{METODE PENELITIAN}

Penelitian ini menggunakan pendekatan penelitian kuantitatif, karena ingin mengetahui dan mengukur variabelvariabel dan tingkat pengaruh variabel yang satu terhadap variabel yang lain, yaitu Brand Image dan Kualitas Layanan hotel terhadap kepuasan pelanggan. Lokasi penelitian adalah Hotel Swiss-Bel yang berlokasi di Sektor 2 Blok SA, Jl. Metro Pondok Indah, Jakarta Selatan.

Jenis penelitian ini adalah jenis penelitian survei eksplanatif. Dan jenis survei ini akan digunakan apabila peneliti ingin mencari tahu mengapa kondisi tertentu itu bisa terjadi atau apa yang melibatkan pengaruh-pengaruh itu bisa terjadi. Survei adalah suatu penelitian kuantitatif dengan menggunakan berbagai pertanyaan terstruktur yang dibagikan kepada banyak orang, lalu kemudian diolah, dan dianalisis oleh peneliti. Berbagai pertanyaan terstruktur itu dikenal dengan istilah kuesioner.

Seperti dijelaskan sebelumnya, penelitian ini bertujuan untuk mendeskripsikan Brand Image dan kualitas pelayanan hotel pada kepuasan pelanggan. Salah satu dari berbagai Hotel di Jakarta Selatan yang lokasinya sangat strategis untuk kemana-mana termasuk ke mall, tempat wisata dan lain-lain, yaitu Hotel Swiss-Bel yang terletak di Pondok Indah, Jakarta Selatan yang merupakan Hotel Internasional bintang empat. Hotel ini dipilih karena menawarkan layanan yang sedang dipelajari dan sebagian besar wisatawan lokal memilih hotel ini. Kuesioner diberikan kepada responden target yang dipilih berdasarkan teknik pengambilan sampel acak sederhana. Kuesioner diberikan selama hari sabtu, hari minggu dan liburan sekolah atau libur tanggal merah. Hotel operator dihubungi terlebih dahulu untuk mendapatkan izin dan memperoleh daftar sebelum mereka menjawab kuesioner. Instrumen survei berisi 35 item.

Pengumpulan semua data akan dilakukan untuk mencapai informasi yang dibutuhkan dalam beberapa langkahlangkah yang harus dilewati. Sumber data yang akan dikumpulkan adalah data primer melalui angket yang dikelola sendiri yang didistribusikan kepada 30 responden di Hotel Swiss-Bel Pondok Indah, Jakarta Selatan.

Data Primer adalah data yang berasal atau bersumber dari data asli. Data Primer ini tidak ada dalam bentuk gabungan atau file-file. Data primer harus dicari melalui narasumber atau seseorang yang akan kita jadikan objek penelitian atau orang yang akan kita jadikan sebagai orang yang mendapatkan informasi atau sebuah data. Oleh karena itu, di dalam penelitian ini data primer didapatkan melalui angket atau kuesioner yang disebarkan langsung kepada responden. Kuesioner yang digunakan oleh peneliti ialah pertanyaan tertutup. Angket atau kuesioner tertutup adalah angket yang dibuat sedetail mungkin untuk mendapatkan data tentang kondisi atau situasi yang dialami oleh responden itu sendiri. Penelitian ini menggunakan skala Likert pada jawaban yang bertujuan untuk memudahkan peneliti membuat analisis secara kuantitatif. Jawaban penelitian responden ini akan diberi skor 1 sampai dengan 5, yaitu Sangat Tidak Setuju (STS) hingga Sangat Setuju (SS).

\section{A. Pengukuran}

Tujuh konstruk yang diukur dalam penelitian ini diperoleh dari pencarian literatur. Itu konstruksi adalah perilaku karyawan, fasilitas kamar, bukti fisik, kualitas makanan, kepuasan pelanggan, citra merek dan niat perilaku. Setiap konstruk berisi lima item.

Tabel 1 Tabel Operasionalisasi Variabel

\begin{tabular}{|c|c|c|}
\hline No. & Atribut & Sumber \\
\hline & PERILAKU KARYAWAN & \multirow{7}{*}{ (Dortyol et al., 2014) } \\
\hline 1. & Staf hotel ramah. & \\
\hline 2. & $\begin{array}{l}\text { Staf hotel tahu pekerjaan mereka, melakukannya dengan baik dan tidak } \\
\text { membuat kesalahan. }\end{array}$ & \\
\hline 3. & Staf hotel sopan. & \\
\hline 4. & Staf hotel selalu tersedia saat dibutuhkan. & \\
\hline \multirow[t]{2}{*}{5.} & Staf hotel memiliki pengetahuan yang dibutuhkan untuk menjawab. & \\
\hline & FASILITAS KAMAR & \\
\hline 1. & Kamarnya sangat nyaman. & \multirow{5}{*}{ (Dortyol et al., 2014) } \\
\hline 2. & Kamar ini memiliki perabotan berkualitas. & \\
\hline 3. & Kamarnya cukup besar. & \\
\hline 4. & Fasilitas di dalam ruangan berfungsi dengan baik. & \\
\hline 5. & Kamar sepi. & \\
\hline & BENTUK FISIK & \multirow{6}{*}{$\begin{array}{l}\text { (Dortyol et al., 2014; Gunarathne, } \\
\text { 2014) }\end{array}$} \\
\hline 1. & Hotel melakukan pemeliharaan rutin hotel ruang rumput dan hijau. & \\
\hline 2. & Bangunan dan tata letak hotel menyenangkan secara visual. & \\
\hline 3. & Hotel ini memiliki ruang yang cukup dan nyaman. & \\
\hline 4. & Perabotan di hotel modern dan nyaman. & \\
\hline 5. & Hotelnya bersih. & \\
\hline
\end{tabular}




\begin{tabular}{|c|c|c|}
\hline & KUALITAS MAKANAN & \multirow{6}{*}{$\begin{array}{l}\text { (Dortyol et al., 2014; Giritlioglu } \\
\text { et al., 2014; Gupta \& Srivastava, } \\
\text { 2011) }\end{array}$} \\
\hline 1. & Makanan hotel lezat. & \\
\hline 2. & Makanan hotel sangat bervariasi. & \\
\hline 3. & Makanan hotel sangat berkualitas. & \\
\hline 4. & Makanan hotel aman untuk dimakan oleh pelanggan. & \\
\hline \multirow[t]{2}{*}{5.} & Makanan disajikan kepada pelanggan sesuai pesanan mereka. & \\
\hline & KEPUASAN PELANGGAN & \multirow{6}{*}{ (Al Khattab \& Aldehayyat, 2011) } \\
\hline 1. & Secara keseluruhan, saya puas dengan layanan hotel. & \\
\hline 2. & Saya puas dengan keputusan saya untuk mengunjungi hotel ini. & \\
\hline 3. & Keputusan saya untuk tinggal di hotel ini adalah keputusan yang bijaksana. & \\
\hline 4. & Saya akan mengatakan hal-hal positif tentang hotel ini. & \\
\hline \multirow[t]{2}{*}{5.} & Saya merasa senang ketika menginap di hotel ini. & \\
\hline & CITRA MEREK & \multirow{6}{*}{ (Padlee, Thaw \& Zulkifli, 2019) } \\
\hline 1. & Peduli pada pelanggan. & \\
\hline 2. & Perusahaan memiliki kesan baik. & \\
\hline 3. & Merek memiliki karakter yang mudah diingat. & \\
\hline 4. & Merek mudah dibayangkan layaknya seseorang. & \\
\hline \multirow[t]{2}{*}{5.} & Merek sesuai dengan karakter. & \\
\hline & PERILAKU NIAT & \multirow{6}{*}{ (Gunarathne, 2014) } \\
\hline 1. & Saya berniat untuk terus tinggal di hotel ini. & \\
\hline 2. & Saya berniat akan merekomendasikan hotel ini kepada orang lain. & \\
\hline 3. & Saya ingin mengulangi menginap di hotel ini di masa depan. & \\
\hline 4. & Saya ingin membeli kembali banyak layanan di hotel ini. & \\
\hline 5. & Saya akan mempertimbangkan hotel ini sebagai pilihan pertama saya. & \\
\hline
\end{tabular}

Sumber: Diadopsi dari Padlee, S.F., Thaw, C.Y., Zulkifli, S.N.A., 2019.

\section{HASIL DAN PEMBAHASAN}

\section{A. Analisis Deskriptif}

Penelitian ini menganalisis data dari responden $(\mathrm{N}=30)$. Berdasarkan analisis, responden terdiri dari mayoritas Pria (54,8\%), dan berusia (35,5\%). Responden terdiri dari mayoritas berstatus Menikah (58,1\%) dan Pendidikan terakhir SMK dan Sarjana memiliki jumlah yang sama yaitu $(45,2 \%)$.

Tabel 2 Data Demografi Responden

\begin{tabular}{|l|l|l|}
\hline & & $\mathrm{F}(\%)$ \\
\hline Jenis Kelamin & Pria & $17(54,8 \%)$ \\
\hline & Wanita & $14(45,2)$ \\
\hline Usia & & \\
\hline & $18-24$ Tahun & $10(32,3 \%)$ \\
\hline & $25-34$ Tahun & $11(35,5 \%)$ \\
\hline & $35-44$ Tahun & $9(29,0 \%)$ \\
\hline & $45-54$ Tahun & $1(3,2 \%)$ \\
\hline Status & 55 tahun ke atas & $0(0 \%)$ \\
\hline & & \\
\hline & Belum Menikah & $13(41,9 \%)$ \\
\hline Pendidikan Terakhir & Menikah & $18(58,1 \%)$ \\
\hline & & \\
\hline & SMP & $0(0 \%)$ \\
\hline & SMK & $14(45,2 \%)$ \\
\hline & Diploma & $3(9,7 \%)$ \\
\hline & Sarjana & $14(45,2 \%)$ \\
\hline
\end{tabular}

Selanjutnya Uji Validitas dan Reliabilitas menunjukkan semua variabel valid dan reliabel. Sebuah instrumen yang valid merupakan instrumen yang benar-benar tepat untuk mengukur apa yang harus diukur. Validitas (Validity) yaitu dimana suatu alat ukur tepat dalam mengukur suatu data dengan kata lain, alat ukur yang dipakai memang mengukur sesuatu yang harus dan ingin diukur. Analisis reliabilitas juga dilakukan untuk menilai apakah skala yang digunakan 
dalam kuesioner itu reliabel. Sebuah kuesioner dikatakan reliabel apabila jawaban dari seseorang terhadap pernyataan tersebut adalah sangat konsisten dan benar apa adanya terhadap situasi yang ada. Cronbach's Alpha adalah ukuran keandalan yang populer yang dapat digunakan untuk menentukan sejauh apakah item kuesioner dapat diperlakukan sebagai konstruk laten tunggal. Analisis faktor dilakukan pada semua 35 item dalam daftar pertanyaan. Untuk tujuan ini, analisis komponen utama dengan rotasi varimax telah diterapkan. Setelah itu, variabel menunjukkan nilai Kaiser-Meyer Olkin (KMO) lebih dari 0.5. Sedangkan nilai Cronbach Alpha seluruh variabel menunjukkan angka diatas 0.7. Hasil uji validitas dan reliabilitas ada di gambar 4 sebagai berikut.

Tabel 3 Hasil Uji Validitas dan Reliabilitas

\begin{tabular}{|l|l|l|l|}
\hline Variabel & KMO & $\mathrm{a}$ & Keterangan \\
\hline Perilaku Karyawan & 0,844 & 0,859 & Valid \\
\hline Fasilitas Kamar & 0,735 & 0,859 & Valid \\
\hline Bukti Fisik & 0,750 & 0,859 & Valid \\
\hline Kualitas Makanan & 0,762 & 0,859 & Valid \\
\hline Kepuasan Pelanggan & 0,654 & 0,859 & Valid \\
\hline Brand Image & 0,735 & 0,859 & Valid \\
\hline Perilaku Niat & 0,712 & 0,859 & Valid \\
\hline
\end{tabular}

Hipotesis dari penelitian ini selanjutnya dilakukan dengan cara analisis regresi linear sederhana. Seluruh hipotesis terbukti dan signifikan secara statistik dengan nilai signifikansi dibawah 0,05. Hipotesis pertama menunjukkan perilaku karyawan secara positif ( $\mathrm{Sig}=0,000)$ dengan besar pengaruh $(\mathrm{R}=0,705)$. Kemudian hipotesis kedua menunjukkan fasilitas kamar secara positif (Sig=0,001) dengan besar pengaruh $(\mathrm{R}=0,517)$. Hipotesis ketiga, menunjukkan bukti fisik secara positif ( $\mathrm{Sig}=0,000)$ dengan besar pengaruh $(\mathrm{R}=0,282)$. Hipotesis keempat, menunjukkan kualitas makanan secara positif ( $\mathrm{Sig}=0,000)$ dengan besar pengaruh $(\mathrm{R}=594)$. Hipotesis kelima, menunjukkan kepuasan pelanggan secara positif $(\mathrm{Sig}=0,024)$ dengan besar pengaruh $(\mathrm{R}=0,773)$. Hipotesis keenam, menunjukkan Brand Image secara positif $(\mathrm{Sig}=0,001)$ dengan besar pengaruh $(\mathrm{R}=0,920)$. Hipotesis terakhir, yaitu perilaku niat secara positif $(\mathrm{Sig}=0,000)$ dengan besar pengaruh $(\mathrm{R}=0,850)$.

Tabel 4 Hasil Uji Regresi Linear

\begin{tabular}{|l|l|l|l|}
\hline Hipotesis & $\mathrm{R}$ & $\mathrm{R}$ Square & Sig \\
\hline $\begin{array}{l}\text { H1 hubungan positif antara perilaku karyawan dan pelanggan } \\
\text { kepuasan }\end{array}$ & 0,705 & 0,497 & 0,000 \\
\hline $\begin{array}{l}\text { H2 hubungan positif antara fasilitas kamar dan kepuasan } \\
\text { pelanggan }\end{array}$ & 0,517 & 0,267 & 0,001 \\
\hline $\begin{array}{l}\text { H3 hubungan positif antara bukti fisik dan kepuasan } \\
\text { pelanggan }\end{array}$ & 0,282 & 0,079 & 0,000 \\
\hline $\begin{array}{l}\text { H4 hubungan positif antara kualitas makanan dan } \\
\text { kepuasan pelanggan }\end{array}$ & 0,594 & 0,353 & 0,000 \\
\hline $\begin{array}{l}\text { H5 hubungan positif antara kepuasan pelanggan dan niat } \\
\text { perilaku }\end{array}$ & 0,773 & 0,597 & 0,024 \\
\hline $\begin{array}{l}\text { H6 hubungan positif antara kepuasan pelanggan dan citra } \\
\text { merek }\end{array}$ & 0,920 & 0,847 & 0,001 \\
\hline H7 hubungan positif antara citra merek dan niat perilaku & 0,850 & 0,722 & 0,000 \\
\hline
\end{tabular}

Penelitian ini menunjukkan hasil dari beberapa konstruksi, berdasarkan uji statistik yang paling mempengaruhi ialah brand image, brand image juga mempengaruhi keputusan pembelian pelanggan. Pembelian pelanggan tertuju karena adanya ketertarikan kepada pelayanan serta fasilitas hotel yang diberikan kepada pelanggan. Keputusan pembelian biasanya dikarenakan pelanggan tersebut telah mengetahui isi atau identitas hotel tersebut dan juga melengkapi kebutuhan customer itu sendiri. Maka dari itu, keputusan pembelian sangat mempengaruhi citra merek dan pada akhir keputusan konsumen akan beranggapan positif tentang merek tersebut. (Ikhsana et al., 2019). Alasan menguji efek dari semua komponen nilai merek pada pengabdian kepada merek adalah bahwa pengabdian ini sudah dianggap sebagai salah satu dari komponen yang sangat penting untuk mempertahankan dan membangun hubungan jangka panjang dengan pelanggan. Meskipun citra merek diakui sebagai kekuatan pendorong aset merek dan kinerja merek, beberapa penelitian telah menguraikan hubungan antara merek citra dan ekuitas merek (Zhang et al., 2011). Nilai merek mengacu pada 
seluruh aset yang dimiliki oleh suatu merek, nilai komponen suatu merek terdiri dari kesadaran pada merek, dipengaruhi oleh merek, kepercayaan pada merek, asosiasi tentang merek, citra merek, dan pengabdian kepada elemen merek.

Citra merek terdiri dari keseluruhan positif atau negatif, emosional atau tayangan estetika yang dibuat oleh suatu produk di pasar sasaran. Berdasarkan definisi ini, dimungkinkan untuk mengklaim bahwa Merek Gambar dibuat di benak sebagai hasil dari persepsi konsumen tentang produk atau layanan dan sebagai hasil dari upaya pemasaran merek. Dengan kata lain, konsumen mungkin memiliki citra di benak mereka dengan bantuan asosiasi tentang merek. Memiliki brand image yang baik untuk sebuah perusahaan adalah hal terpenting bagi sebuah perusahaan dan semua karyawan yang bekerja diperusahaan tersebut, melainkan akan mendapatkan hasil yang positif untuk semua pelanggan yang belum pernah maupun sudah pernah menginap di Hotel Swiss-Bell, misalnya menginap kembali di hotel itu.

Berdasarkan hasil kedua yang mempengaruhi secara positif yaitu perilaku niat. Kutipan oleh Siddiqi (2011) yang menunjukkan bahwa atribut kualitas layanan positif terkait dengan kepuasan pelanggan dan pada akhirnya pun kepuasan pelanggan ini berhubungan sangat baik untuk mendapatkan suatu loyalitas pelanggan. Biasanya, pelanggan hotel yang puas dengan pelayanannya, mereka akan merekomendasikan hotel dengan cara obrolan dari mulut ke mulut kepada keluarga atau orang lain. Dengan kembali tinggal di hotel yang sama dan yang lainnya telah dipengaruhi tinggal di hotel, ini berkontribusi pada profitabilitas di lebih dari satu cara (Petzer \& Mackay, 2014). Dengan kembali tinggal di hotel yang sama dan yang lainnya telah dipengaruhi tinggal di hotel, ini berkontribusi pada profitabilitas di lebih dari satu cara (Petzer \& Mackay, 2014) Niat perilaku sendiri pun sudah tertanam di hati pelanggan jika pelanggan itu mendapatkan sesuatu yang baik dari dalam perusahaan baik dari segi perilaku karyawan atau perilaku kondisi fisik hotel maupun makanan, jika pelanggan merasa sangat puas setelah menginap disebuah hotel tersebut, maka aka nada perilaku niat untuk menginap kembali di hotel tersebut dan merekomendasikan kepada orang lain.

Pengaruh ketiga yang memberikan pengaruh secara positif yaitu kepuasan pelanggan, Oleh karena itu, kepuasan pelanggan sebagai hasil dari layanan berkualitas yang disediakan sangat penting bagi operator hotel karena secara langsung dapat mempengaruhi loyalitas pelanggan, niat perilaku dan mempertahankan citra merek (brand image). Mereka juga merasa puas ketika nilai layanan yang mereka terima cocok harga yang mereka bayar untuk layanan (Lu et al., 2015; Wicks \& Roethlein, 2009) Dalam urutan untuk mengoperasikan hotel dengan sukses sehingga memberikan pelanggan pengalaman yang memuaskan, hotel manajer perlu mengetahui apa yang diinginkan atau disukai oleh pelanggan dan bagaimana pelanggan itu menilai layanan hotel tersebut. (Olorunniwo et al., 2006). Pelanggan sendiripun akan merasa puas jika pelanggan itu sendiri merasa dipuaskan saat menginap disebuah hotel tersebut. Mulai dari segi makanan yang lezat, bukti fisik hotel yang bagus atau unik, perilaku karyawan yang sopan dan ramah, dan dari segi mana saja yang membuat pelanggan itu puas.

\section{KESIMPULAN}

Pengetahuan tentang adanya hubungan antara kualitas layanan dan kepuasan pelanggan dapat membantu manajer untuk mengatasi tantangan peningkatan kualitas layanan di hotel industri. Dengan demikian, penelitian ini telah berkontribusi pada tubuh teori pengetahuan tentang Brand Image dan kualitas pelayanan hotel terhadap kepuasan pelanggan di Hotel yang terletak di tengah kota. Penelitian ini meneliti sampai sejauh mana masing-masing dari empat dimensi kualitas layanan (perilaku karyawan, fasilitas kamar, bukti fisik dan kualitas makanan) mempengaruhi kualitas pelayanan hotel terhadap kepuasan pelanggan Hotel Swiss-Bel yang berlokasi di Sektor 2 Blok SA, Jl. Metro Pondok Indah, Jakarta Selatan. Temuan memperkirakan kepuasan pelanggan sebagai hasil faktor kualitas pelayanan tertinggi evaluasi oleh pelanggan di Hotel Swiss-bel, Pondok Indah. Ini. Dalam penelitian terdahulu identifikasi bukti fisik tidak menghasilkan pengaruh yang signifikan terhadap kepuasan pelanggan.

Berdasarkan hasil analisis ini menyatakan bahwa operator hotel perlu berkonsentrasi pada cara menambah atau mempertahankan kepuasan pelanggan karena faktor ini pada akhirnya dapat merangsang niat berperilaku positif untuk diwujudkan, seperti kesetiaan pelanggan dan perilaku untuk niat merekomendasikan kepada keluarga maupun orang lain. Maka dalam penelitian ini diketahui bagaimana pelanggan dapat memahami kualitas layanan dan mampu mengukur kualitas layanan yang dapat menguntungkan dalam hal mengelola layanan hotel dengan memperoleh sarana untuk mengukur kualitas layanan yang dapat membantu manajemen hotel memperoleh data yang dapat digunakan untuk memantau dan meningkatkan kualitas layanan secara konsisten. Penelitian ini memungkinkan operator hotel untuk mendapatkan pemahaman secara lengkap dan yang lebih baik tentang bagaimana seluruh masing-masing dimensi kualitas pelayanan mempengaruhi kepuasan pelanggan. Studi ini telah dibatasi oleh keterbatasan seperti hanya berfokus pada Hotel di tengah kota di Pondok Indah, Jakarta Selatan (yaitu, Hotel Swiss-Bel). Sementara rekomendasi ini berlaku untuk hotel-hotel lain yang berlokasi di daerah pinggiran kota lainnya masih dapat menerapkannya karena mereka juga memberikan informasi umum tentang cara untuk meningkatkan kualitas layanan perhotelan. Penelitian di masa depan perlu dilakukan untuk mencari tahu pengaruh dimensi kualitas layanan yang lainnya yang cenderung memiliki niat untuk membahagiakan dan membuat kepuasan pelanggan yang jauh lebih baik. Penelitian ini juga dapat dilakukan di berbagai daerah karena hasilnya mungkin berbeda sesuai dengan negara atau kota. 


\section{DAFTAR PUSTAKA}

Aldehayyat, Jehad. (2011). Organisational characteristics and the practice of strategic planning in Jordanian hotels. International Journal of Hospitality Management - INT J HOSP MANAG. 30. 192-199. 10.1016/j.ijhm.2010.05.001.

Angelova, B., and Zekiri, J. (2011), "Measuring Customer Satisfaction with Service Quality Using American Customer Satisfaction Model (ACSI Model)", International Journal of Academic Research in Business and Social Sciences, Vol. 1, No. 3, pp. 232-258.

Atmaja, Suhendra, and Poppy Ruliana. "Strategi Promosi Hotel melalui Wisata Syariah dalam Meningkatkan Kualitas Pelayanan Jasa.” Inter Komunika, vol. 2, no. 2, 2017, pp. 182-191, doi:10.33376/ik.v2i2.38.

Ardahaey, F.T. (2011), "Economic Impacts of Tourism Industry”, International Journal of Business and Management, Vol. 6, No. 8, pp. 206-215.

Caber M.; Albayrak T. (2014), “Does the importance of hotel attributes differ for senior tourists?”, International Journal of Contemporary Hospitality Management, Vol. 26, No. 4, pp. 610-628. DOI: https://doi.org/10.1108/ IJCHM-02-2013-0103

Caruana, A. (2002), "Service loyalty: The effects of service quality and the mediating role of customer satisfaction", European journal of marketing, Vol. 36, No. 7/8, pp. 811-828.

Dedeoglu, B.B., and Demirer, H. (2015), "Differences in service quality perceptions of stakeholders in the hotel industry", International Journal of Contemporary Hospitality Management, Vol. 27, No. 1, pp. 130-146.

Dortyol, I.T., Varinli, I., and Kitapci, O. (2014), “How do international tourists perceive hotel quality?", International Journal of Contemporary Hospitality Management, Vol. 26, No. 3, pp. 470-495.

Giritlioglu, I., Jones, E., and Avcikurt, C. (2014), "Measuring food and beverage service quality in spa hotels: A case study in Balıkesir, Turkey”, International Journal of Contemporary Hospitality Management, Vol. 26, No. 2. pp. 183-204.

Gunarathne, U. (2014), "Relationship between Service Quality and Customer Satisfaction in Sri Lanka Hotel Industry”, International Journal of Scientific and Research Publications, Vol. 4, pp. 1-8.

Gupta, P., and Srivastava, R. (2011), Analysis of Customer Satisfaction in Hotel Service Quality Using Analytic Hierarchy Process (AHP), International Journal of Industrial Engineering Research and Development, Vol. 2, No. 1, pp. 59-68.

Han H.; Back K. (2008), "Relationships among image congruence, consumption emotions, and customer loyalty in the lodging industry", Journal of Hospitality \& Tourism Research, Vol. 32, No. 4, pp. 467-490. DOI: https://doi. org/10.1177/1096348008321666

Ikhsana, Putri D., et al. "Penerapan Strategi E-marketing Communication dan Ekuitas Merek Siaranku.com terhadap Loyalitas Viewers." Inter Komunika, vol. 4, no. 1, 2019, pp. 58-74, doi:10.33376/ik.v4i1.217.

Kandampully, J., Juwaheer, T.D., \& Hu, H.H. (2011), “The influence of a hotel firm's quality of service and image and its effect on tourism customer loyalty”, International Journal of Hospitality \& Tourism Administration, Vol. 12, No. 1, pp. 21-42.

Karunaratne, W.M., and Jayawardena, L.N. (2010), “Assessment of Customer Satisfaction in a Five Star Hotel”, Tropical Agricultural Research, Vol. 21, No. 3, pp. 258-265.

Lu, C., Berchoux, C., Marek, M.W., and Chen, B. (2015), "Service quality and customer satisfaction: qualitative research implications for luxury hotels", International Journal of Culture, Tourism and Hospitality Research, Vol. 9, No. 2, pp. 168-182.

Mamilla, R., Janardhana, G., and Anjan, B.G. (2013), “Customer Satisfaction on Reliability Dimension of Service Quality in Indian Higher Education”, International Journal of Industrial and Manufacturing Engineering, Vol. 7, No. 12, pp. 3210-3215.

Markovic, S., and Jankovic, S. R. (2013), “Exploring The Relationship Between Service Quality and Customer Satisfaction in Croatian Hotel Industry", Tourism and Hospitality Management, Vol. 19, No. 2, pp. 149-164.

Naseem, A., Ejaz, S., and Malik, P.K. (2011), “Improvement of Hotel Service Quality: An Empirical Research in Pakistan”, International Journal of Multidisciplinary Sciences and Engineering, Vol. 2, No. 5, pp. 52-56.

Olorunniwo, F., Hsu, M.K., and Udo, G.J. (2006), "Service quality, customer satisfaction, and behavioral intentions in the service factory", Journal of Services Marketing, Vol. 20, No. 1, pp. 59-72. 
Padlee, S.F., Thaw, C.Y., Zulkiffli, S.N.A. (2019), "The Relationship between Service Quality, Customer Satisfaction and Behavioral Intentions in the hospitality Industry, Tourism and Hospitality Management, Vol. 25, No.1, 010303.

Parasuraman, A., Zeithaml, V.A., and Berry, L.L. (1994), "Reassessment of expectations as a comparison standard in measuring service quality: implications for further research", The Journal of Marketing, pp. 111-124.

Pramadivara. I.M.G dan N.K Seminari. 2012. Pengaruh Kualitas Pelayanan Terhadap Kepuasan Konsumen Pada Puri Saron Hotel Seminyak Kuta. 494-509.

Petzer, D., and Mackay, N. (2014), "Dining atmospherics and food and service quality as predictors of customer satisfaction at sit-down restaurants", African Journal of Hospitality, Tourism and Leisure, Vol. 3, No. 2, pp. 1-14.

Rao, S., and Sahu, P.C. (2013), “Impact of Service Quality on Customer Satisfaction in Hotel Industry”, IOSR Journal Of Humanities And Social Science (IOSR-JHSS), Vol. 18, pp. 39-44.

Siddiqi, K.O. (2011), "Interrelations between Service Quality Attributes, Customer Satisfaction and Customer Loyalty in the Retail Banking Sector in Bangladesh", International Journal of Business and Management, Vol. 6, No. 3, pp. 12-36.

Sovani, Jesi T., et al. "Pengaruh Penerapan Corporate Social Responsibility (CSR) Terhadap Citra Merek, Kepercayaan Merek Dan Loyalitas Merek (Survei Pada Masyarakat Sekitar PT. Tirta Investama, Desa Keboncandi, Kecamatan Gondang Wetan, Kabupaten Pasuruan)" Profit: Jurnal Administrasi Bisnis Universitas Brawijaya, vol. 10, no. 1, 2016, pp. 24-33.

Wicks, A., and Roethlein, C. (2009), “A satisfaction-based definition of quality”, Journal of Business \& Economic Studies, Vol. 15, No. 1, pp. 82-97.

Zhang, Z., Ye, Q., and Law, R. (2011). "Determinants of Hotel Room Price”, International Journal of Contemporary Hospitality Management, Vol. 23, No. 7, pp. 972-98. 